\title{
Questionnaire to assess the knowledge of health professionals about the leisure physical activities of pregnant women
}

\section{Questionário para avaliação do conhecimento de profissionais da saúde sobre atividades físicas de lazer para gestantes}

Silvio Aparecido Fonseca', Juliana Rafaela Andrade da Silva², Emmanuelly Correia de Lemos², Mauro Virgílio Gomes de Barros²

\begin{abstract}
The purpose of this study was to describe the construction, validation, reproducibility, classification and ways to use the Questionnaire for Assessment of Health Professionals' Knowledge of Leisure Physical Activities in Pregnant Women, denominated QCAF-PROFI | LG. This is an operations study aimed at innovation as a result of knowledge produced in the SUS + Active Project. The QCAF-PROFI | LG was created with three dimensions, six indicators and 14 previously validated questions from the Questionnaire for Assessment of Interventions Promoting Physical Activity in Primary Health Care (AIPAF | ABS). Face validity and content, based on the AIPAF | ABS, showed good adaptation of the writing / language of the questions (mean 2.5; maximum score $=3.0$ ), response scale adequacy (mean 2.5; maximum $=3.0$ ) and overall assessment of the quality questionnaire (mean 3.6; maximum score $=4)$. With respect to reproducibility of the QCAFPROFI | LG, mean values of 0.55 (Spearman's rho $=0.29$ to 0.81; professional knowledge dimension), 0.76 (sociodemographic dimension) and 1.00 (initial training dimension) were obtained. The questionnaire provides two processes for data production and interpretation, resulting in eight measures with scores and categorical metrics for verified and perceived levels of knowledge about the leisure physical activities of pregnant women (LPAPW). The QCAF-PROFI | LG exhibited satisfactory "test-retest" reproducibility and validity, and may be useful in women's health and for the development of a line of research on physical activity and maternal and child health.
\end{abstract}

\section{Keywords}

Motor Activity; Pregnancy; Knowledge; Maternal and Child Health.

\section{Resumo}

O objetivo foi descrever os processos de construção, validação, reprodutibilidade, classificação e formas de utilização do Questionário para Avaliação do Conhecimento de Profissionais da Saúde sobre Atividades Físicas de Lazer para Gestantes, denominado QCAF-PROFI $\mid L G$. Trata-se de uma pesquisa operativa com fins de inovação, a partir de conbecimentos produzidos no Projeto SUS +Ativo. O QCAF-PROFI $\mid L G$ foi construído a partir da seleção de três dimensões, seis indicadores e 14 questões previamente validadas do Questionário para Avaliação de Intervenções para Promoção da Atividade Física na Atenção Básica à Saúde (AIPA$F \mid A B S)$. A validade de face e conteúdo, baseada no AIPAF $\mid A B S$, evidenciou boa adequação da redação/linguagem das perguntas (média de 2,5; pontuação máxima=3,0), do nível de adequação das escalas de respostas (média de 2,5; pontuação máxima =3,0) $e$ da avaliação geral do grau de qualidade do questionário (média de 3,6; pontuação máxima=4). Quanto à reprodutibilidade do QCAF-PROFI $\mid L G$, observaram-se valores médios de 0,55 (Spearman's rho $=0,29$ a 0,81; dimensão conbecimento profissional), 0,76 (dimensão sociodemográfica) e 1,00 (dimensão formação inicial). O uso do questionário permite dois processos de obtenção e interpretação dos dados, resultando em oito medidas com escores e métricas categóricas dos níveis de domínio aferido e percebido do conhecimento sobre LPAPW. O QCAF-PROFI $\mid L G$ apresentou resultados satisfatórios de reprodutibilidade "teste-reteste" e validade, podendo ser útil à linha de cuidados da saúde da mulher e ao desenvolvimento da linha de pesquisas em atenção à atividade física e saúde materno-infantil.

\section{Palavras-chave}

Atividade motora; Gravidez; Conhecimento; Saúde materno-infantil.

\section{Introduction}

The benefits of leisure physical activity for maternal ${ }^{1-4}$

1 Universidade Estadual de Santa Cruz, Departamento de Ciências da Saúde, Ilhéus, BA, Brazil.

2 Universidade de Pernambuco, Escola Superior de Educação Física, Recife, PE, Brazil. and fetal ${ }^{5-8}$ outcomes are well documented in the literature. However, the level of leisure physical activities in pregnancy is low l, $^{5,9-11}$. Moreover, little is known about the effectiveness of interventions in promoting physical activity for pregnant women, as revealed in a 
systematic review conducted by Pearce et al. ${ }^{12}$. However, the efforts of nine countries, reflected in eleven sets of guidelines related to leisure physical activity during pregnancy ${ }^{13}$ may facilitate understanding of its promotion for pregnant women.

Leisure physical activity for pregnant women (LPAPW) is one of the initiatives aimed at social actors (recipients and promoters) involved in maternal and child health. Its purpose is to enhance knowledge, skills, attitudes and leisure physical activity levels using informative, behavioral, social, environmental and political approaches that have a positive impact on the supply, access, adherence and coverage of actions. LPAPW involves the reciprocal efforts of recipients (pregnant women and family members) and promoters (politicians, managers, health workers and researchers). To that end, structured processes are used in the formation, intervention, work environment and research vectors, primarily in the physical education and health areas ${ }^{14}$.

Although knowledge in itself is not sufficient to promote physical activity, it seems reasonable to assume that knowledge is a necessary condition in social actors for successful interventions. Furthermore, professional knowledge is a predisposing factor for permanent health education ${ }^{15}$. In this respect, and starting from the premise that conceptual or disciplinary knowledge about the effects, indications and contraindications of physical activity ${ }^{16}$ should be inherent to the work processes of physical education professionals and those from related areas, it is important to better understand the knowledge of these workers regarding aspects inherent to pregnancy.

National ${ }^{17,18}$ and international ${ }^{19-21,29}$ studies have directly or indirectly investigated the knowledge of health professionals about leisure physical activities for pregnant women. However, these studies were aimed at professionals working in maternal and child healthcare areas (for example: obstetricians, nurses), without considering physical education professionals. Some of these questionnaires ${ }^{17-21,29}$, are lengthy, with no instructions to interpret or passive metrics to classify. As yet, there is no short questionnaire to measure basic knowledge of LPAPW in different professionals and students in the health area working in clinical or community settings.

Given this gap, the aim of this study was to describe the processes of construction, classification and ways to use the Questionnaire for Assessment of Interventions Promoting Physical Activity in Primary Health Care, denominated QCAFPROFI|LG.

\section{Method}

This operations study ${ }^{22}$ with innovative characteristics ${ }^{23}$ is based on one of the questionnaires used in the SUS +Active Project. The SUS + Active Project (approved by the University of Pernambuco Human Research Ethics Committee - CAAE: 13373313.5.0000.5207), has a cross-sectional design and is applied state-wide to assess macroprocesses regarding the operationalization, professional competencies and management of physical activity programs and interventions developed by Basic Health Care in Pernambuco.

To collect SUS + Active Project data, four questionnaires, denominated Questionnaires for the Assessment of Interventions Promoting Physical Activity in Primary Health Care (AIPAF | ABS) ${ }^{24}$, were compiled to assess users, managers, health professionals and the environment. The instrument aimed at professionals contained questions on all the life cycles, including information related to the target group of the present study: pregnant women. Some of these questions were used to construct the Questionnaire for Assessment of Health Profession- 
als' Knowledge of Leisure Physical Activities in Pregnant Women, denominated QCAF-PROFI $\mid \mathrm{LG}^{25}$, and the focus of this article.

The creation of the AIPAF $\mid$ ABS questionnaire ${ }^{24}$, professional version, involved four stages: $1^{\text {st }}$ ) matrix construction; $2^{\text {nd }}$ ) face and validity content; $3^{\text {rd }}$ ) clarity and applicability; and, $4^{\text {th }}$ ) analysis of reproducibility. The process was conducted by researchers from four higher education institutions, supported by 19 external consultants from different fields of knowledge, with experience in assessing health services or investigating physical activity and health, epidemiologists, physical education professionals with experience in basic health care or a multiprofessional residency in health.

The consultants conducted matrix analyses and face and content validation of the AIPAF $\mid$ ABS questionnaire ${ }^{24}$ (stages 1 and 2 ) considering three indicators with response options on a Likert scale, as follows: 1) question comprehension (not comprehensible, somewhat comprehensible, comprehensible, very comprehensible); 2) suitability of response scales (not suitable, somewhat suitable, suitable and very suitable); and, 3) overall assessment of questionnaire quality (very poor, poor, fair, good, very good). Additional comments from consultants regarding questionnaire changes they deemed pertinent were encouraged.

Next, the research team adjusted the questions in accordance with consultants' suggestions and proceeded to stage 3 (clarity and applicability). To that end, the professionals involved in programs and community interventions in Metropolitan Recife were recruited to take part in a pilot study, in order to analyze question/ response inconsistencies and adjust logistical issues for future data collections. Next, the AIPAF $\mid$ ABS questionnaire ${ }^{24}$ was applied and reapplied (test-retest), with 20 health professionals completing the self-reporting instruments one week apart. Spearman's statistical analysis was used and relevant questions were selected by the researchers (Chart 1) to construct the QCAF-PROFI|LG ${ }^{25}$.

Among the three components, 16 dimensions and 151 questions from the AIPAF $\mid$ ABS questionnaire ${ }^{24}$, three dimensions, six indicators and 14 questions $(0.09 \%)$ were selected for the QCAF-PROFI $\mid \mathrm{LG}^{25}$, with a larger number of questions $(\mathrm{n}=10)$ in the professional knowledge dimension. Three questions were chosen for the sociodemographic and one for the initial training dimension (Chart 1).

Among the eight professional knowledge questions used to produce a score were four closed questions that can be complemented by open questions (Chart 2 - 1.1; 6.1; 7.1; 8.1), provided the respondent selects the first response option. Values were assigned for each QCAF-PROFI $\mid \mathrm{LG}^{25}$ response option, (Chart 2) to obtain a score. Next, forms of classifying (Figure 1) and interpreting (Figure 2) knowledge levels were created (Figure 2).

\section{Results}

Nineteen consultants (68\% men) issued 42 opinions regarding the AIPAF-ABS questionnaire matrix and, of these, 13 also conducted face and content analysis (61\% men). Twenty professionals (60\% men) completed the reproducibility stage of the questionnaire.

In relation to face and content validity information, general data from the AI$\mathrm{PAF} \mid \mathrm{ABS}$ questionnaire ${ }^{24}$ showed that the questions contained good language and writing (mean of 2.54 points; maximum score $=3.0$ ), response scales (mean of 2.46 points; maximum score $=3.0$ ) and overall quality of each questionnaire (mean of 3.60 points; maximum score $=4$ ).

With respect to reproducibility of the QCAF-PROFI|LG, mean values were 0.55 (Spearman's $r h o=0.29$ to 0.81 ; professional knowledge dimension - Table 1), 0.76 (sociodemographic dimension) and 100 (initial training dimension). 


\begin{tabular}{|c|c|c|c|}
\hline Dimension & Indicator & Questionnaire of origin & Questions of origin \\
\hline \multirow{3}{*}{ Sociodemographic } & Sex & \multirow{6}{*}{$\begin{array}{l}\text { Questionnaire for Assessment of } \\
\text { Interventions Promoting Physical } \\
\text { Activity in Primary Health Care } \\
\text { (AIPAF } \mid \text { ABS) })^{24}\end{array}$} & A1 \\
\hline & Age & & $\mathrm{A} 2$ \\
\hline & Schooling & & A3 \\
\hline Initial training & Undergraduate course & & B2 \\
\hline \multirow{2}{*}{$\begin{array}{l}\text { Professional } \\
\text { knowledge }\end{array}$} & Level of Verified Knowledge & & E4 to E11 \\
\hline & Level of Perceived Knowledge & & $\mathrm{E} 12$ and E13 \\
\hline $\begin{array}{l}3 \\
\text { dimensions }\end{array}$ & $\begin{array}{l}6 \\
\text { indicators }\end{array}$ & $\begin{array}{l}1 \\
\text { source }\end{array}$ & 14 questions \\
\hline
\end{tabular}

CHART 1 - Matrix of the Questionnaire for Assessment of Health Professionals' Knowledge of Leisure Physical Activities in Pregnant Women, denominated QCAF-PROFI.

TABLE 1 - Reproducibility (test and retest) of questions from the Questionnaire for Assessment of Health Professionals' Knowledge of Leisure Physical Activities in Pregnant Women, denominated QCAF-PROFI|LG.

\begin{tabular}{lcc}
\hline Questions & Spearman's (rho) & P-value \\
\hline Types of LPAPW not recommended & 0.68 & $<0.01$ \\
\hline Weekly frequency of LPAPW & 0.40 & 0.07 \\
\hline Duration of LPAPW sessions & 0.29 & 0.21 \\
\hline Type of LPAPW session & 0.50 & 0.02 \\
\hline Intensity of LPAPW & 0.77 & $<0.01$ \\
\hline Knowledge of Perceived Domain Benefits of LPAPW & 0.81 & $<0.01$ \\
\hline Knowledge of Perceived Domain Recommendations of LPAPW & 0.58 & $<0.01$ \\
\hline
\end{tabular}

n=20. LPAPW = Leisure Physical Activities for Pregnant Women.

As demonstrated in Chart 2, different values are arbitrarily attributed to some questions, as a function of their degree of difficulty. One point is awarded for each correct response and in questions where the respondent had to give 3 answers (one closed and 2 open). The score can vary from 0 to 3 points. Thus, six measures of LPAPW knowledge can be obtained.

The Overall Score for Knowledge of Leisure Physical Activity for Pregnant Women (ECAFL-GG) is obtained by adding the scores of eight questions, which can range from 0 to 18 points. The Overall Score for Knowledge of Leisure Physical Activity Benefits for Pregnant Women (ECAFL-BG), with scores between 0 and 6 points, is derived from the sum of questions C6 and C7. The Score for Knowledge of Leisure Physical Activity Recommendations for Pregnant Women (ECAFL-RG), ranging between 0 and 12 points, is obtained from the sum of questions $\mathrm{C} 1, \mathrm{C} 2$, C3, C4, C5 and C8.

Based on these scores, cutoff points are arbitrarily attributed by dividing the maximum value of each score into three equal parts, resulting in three categorical measures of the knowledge level and respective classifications. In the first, denominated Knowledge Level of Leisure Physical Activities for Pregnant Women (NDA|CAFL-GG), knowledge is categorized as follows: 0 to 6 points = unsatisfactory; 7 to 12 points = intermediate; and 13 to 18 points = satisfactory. In the second, denominated Knowledge Level of Leisure Physical Activity Benefits for Pregnant Women (NDA|CAFL-RG), knowledge is categorized as follows: 0 to 2 points = unsatisfactory; 3 to 4 points $=$ intermediate; and 5 to 6 points = satisfactory. Finally, in the third measure, the Knowledge Level of Leisure Physical Activity Recommendations for Pregnant 


\section{Questions}

C1. Can pregnant women engage in

all types of leisure physical activities?

C1.1. If your answer is no, please name at least two types of physical activities that pregnant women CANNOT engage in:

C2. Do you know how many days a week (minimum) pregnant women should engage in leisure physical activities to obtain maternal and child health benefits?

C3. For pregnant women, do you know how long (minimum) a leisure achieve maternal and fetal benefits?

C4. How does the leisure physical activity need to be structured to provide health benefits to pregnant women?

C5. What is the recommended degree of exertion (intensity) for leisure physical activities in pregnant women? physical activity session should last to

Criteria and scoring [correct response in bold]

[0] I do not know

[1] No

[0] Yes

Not recommended Physical activities (PA) are those contained in the set of guidelines organized by Evenson et al. (2014) ${ }^{13}$. For each correct answer, score 1, for a total of 2 points. Incorrect answers do not lower the score. The maximum score of two assessment parameters (Questions C1 and C1.1) is 3 points.

In relation to weekly frequency of PA

[0] I do not know

[0] The number of days does not matter

[0] Pregnant women should not engage in physical activities

$[0] 1 \quad[0] 2$ [0] $3 \quad$ [0] 4

[2] 5 [0] 6 [0] 7

In relation to the duration of PA sessions

[0] I do not know

[0] The duration of the session does not matter

[0] Pregnant women should not engage in physical activities

[0] $<10 \mathrm{~min}$ [0] $10 \mathrm{~min}$ [0] $20 \mathrm{~min}$ [1] $30 \mathrm{~min}$

[0] $40 \mathrm{~min}$ [0] $60 \mathrm{~min}$

In relation to the type of PA sessions

[0] I do not know

[0] Pregnant women should not engage in physical activities

[0] Only one session per day

[0] Two or 3 daily sessions with the same duration

[1] It can be a single session per day or 2 or 3 sessions throughout the day

In relation to the intensity of $\mathrm{PA}$

[0] I do not know

[0] The intensity/exertion of the physical activity for pregnant women to obtain health benefits does not matter; what is important is to engage in some type of physical activity

[0] Pregnant women should not engage in physical activities

[0] Mild

[2] Moderate (Ex. Physical exertion that makes a person breathe A

LITTLE faster than normal)

[0] Vigorous (Ex. Physical exertion that makes a person breathe MUCH faster than normal)

${ }^{*}$ C6. Does engaging in physical activities during pregnancy provide health benefits to the mother? ${ }^{*}$ C6.1. If your answer is yes, name at least two benefits that you know:

In relation to the benefits of PA for the mother's health

[0] I do not know

[0] No

[1] Yes

6.1.The correct benefits are those listed in the QCAF-PROFI LG ${ }^{25}$ tutorial. For each benefit correctly listed score 1 point, for a total of 2 points. Incorrect answers do not lower the score. The maximum score of two assessment parameters (Questions C6 and C6.1) is 3 points.

${ }^{*}$ C7. Can engaging in physical activities during pregnancy provide benefits to the fetus?

In relation to the benefits of $\mathrm{PA}$ for fetal health

[0] I do not know

[0] No

[1] Yes

${ }^{*}$ C7.1. If your answer is yes, name at least two benefits that you know:

7.1. The correct benefits are those listed in the QCAF-PROFI|LG 25 tutorial. For each benefit correctly listed score 1 point, for a total of 2 points. Incorrect answers do not lower the score. The maximum score of two assessment parameters (Questions C7 and C7.1) is 3 points.

C8. Are there absolute contraindications for engaging in physical exercises during pregnancy?

C8.1. If your answer is yes, name at least two contraindications that you know:

[0] I do not know

[0] No, there are no absolute contraindications

[1] Yes

8.1. The correct absolute contraindications for engaging in physica exercises are those contained in the set guidelines organized by Evenson et al. (2014) ${ }^{13}$. For each absolute contraindication listed, score 1 , for a total of 2 points. Incorrect answers do not lower the score. The maximum score of two assessment parameters (Questions C8 and C8.1) is 3 points.

CHART 2 - Questions and respective values attributed to the knowledge of health professionals about leisure physical activity in pregnancy.

*Questions related to benefits. The others refer to LPAPW recommendations. 
Women (NDA $\mid$ CAFL-RG), knowledge is categorized as follows: 0 to 4 points = unsatisfactory; 5 to 8 points = intermediate; and 9 to 12 points = satisfactory.

Two measures of the knowledge level of leisure physical activities for pregnant women (questions C9 and C10 of the QCAF-PROFI|LG ${ }^{25}$ ) were also obtained: Perceived Level of Knowledge about Leisure Physical Activity Benefits for Pregnant Women (NDP $\mid$ CAFL-BG) and Perceived Knowledge Level of Leisure Physical Activity Recommendations for Pregnant Women (NDP $\mid$ CAFL-RG). To that end, the response scales were grouped and classified as follows: Unsatisfactory = Very Low or Low; Intermediate $=$ Medium; Satisfactory $=$ High; Very High. It is important to underscore that in contrast to the procedure adopted in the verified level of knowledge, no overall indicator of perceived knowledge level was obtained.

The entire process used to attribute and convert values of previously reported classifications are presented in figure 1.

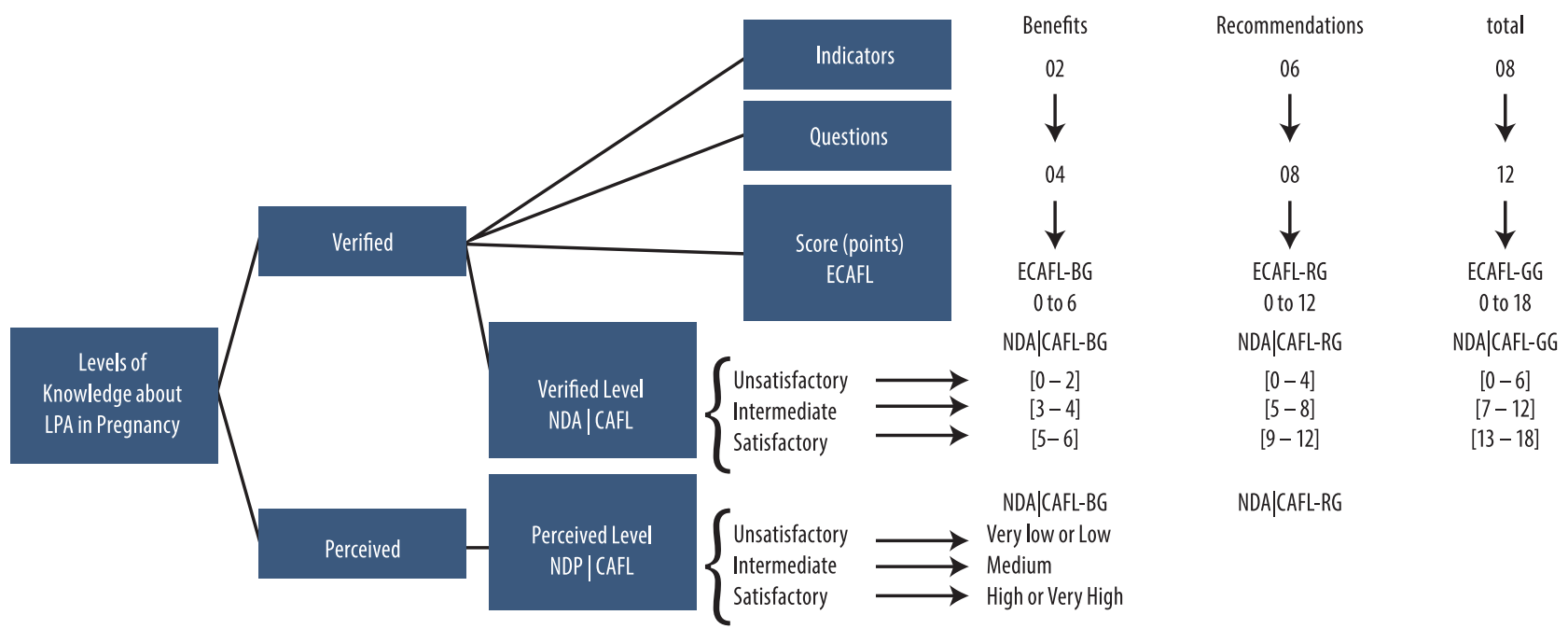

FIGURE 1 - Classification model of knowledge levels regarding leisure physical activity in pregnancy.

ECAFL-GG= Overall Score for Knowledge of Leisure Physical Activity for Pregnant Women; ECAFL-BG= Score for Knowledge of Leisure Physical Activity Benefits for Pregnant Women; Score for Knowledge of Leisure Physical Activity Recommendations for Pregnant Women; NDA|CAFL-GG= Level of Knowledge of about Overall Leisure Physical Activity Benefits for Pregnant Women; NDA|CAFL-BG= Verified Level of Knowledge of about Leisure Physical Activity Benefits for Pregnant Women; NDA|CAFL-RG=Verified Level of Knowledge about Leisure Physical Activity Recommendations for Pregnant Women; NDP|CAFL-BG= Perceived Level of Knowledge about Leisure Physical Activity Benefits for Pregnant Women; NDP|CAFL-RG=Perceived Level of Knowledge about Leisure Physical Activity Recommendations for Pregnant Women.

The QCAF-PROFI|LG ${ }^{25}$ is self-administered, with the help and supervision of the researcher. After data are obtained, there are two processes to collect and interpret knowledge levels of leisure physical activity in pregnancy (Figure 2), with a larger number of questions and greater effort required to obtain measures for the Measured Level of LPAPW ( $\mathrm{n}=6$ ), compared to the Perceived Level of LPAPW ( $\mathrm{n}=2)$.

\section{Discussion}

The Questionnaire for Assessment of Health Professionals' Knowledge of Leisure Physical Activities in Pregnant Women (QCAF-PROFI|LG) exhibited a moderate level of reproducibility and favorable face and content validity indicators.

It was possible to construct a short simple questionnaire with a combination of multiple-choice and open responses, but care is required care while correcting questions and interpreting results, particularly questions related to knowledge. Thus, a brief tutorial ${ }^{25}$ with complementary information (indicating the benefits of physical activity for pregnant women and their children, a link to the primary 


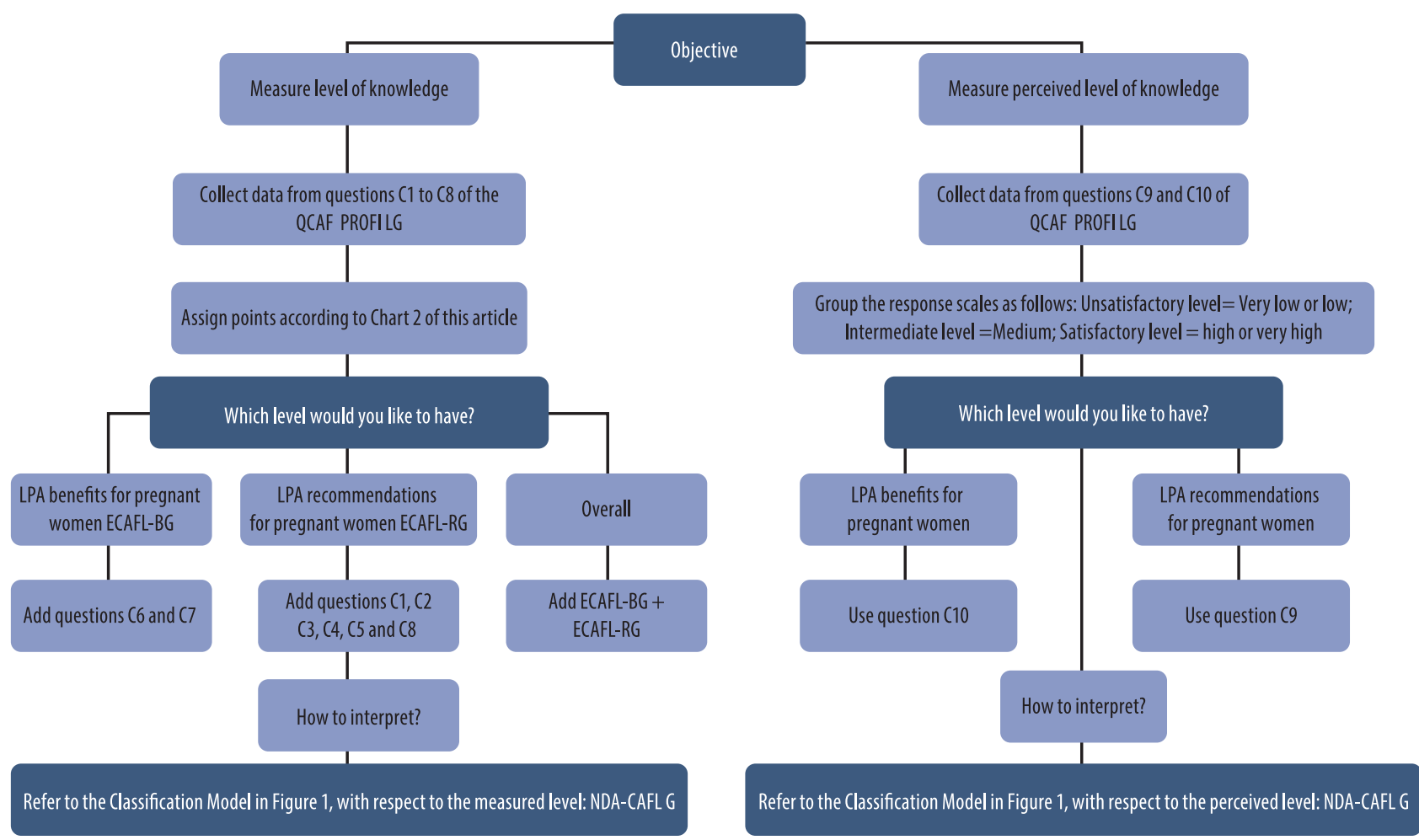

FIGURE 2 - Instruction Protocol to obtain and interpret knowledge levels of leisure physical activity in pregnancy.

reference and a definition of terms) was also produced and made available to facilitate the work of researchers and other interested parties.

Some of the studies ${ }^{17-21,26}$ sought to assess knowledge in a secondary manner, using questions related to the clinical practices of professionals, without providing a score that could be used to compare research. The QCAF-PROFI $\mid \mathrm{LG}^{25}$, in turn, provides comparable indicators and scores on basic knowledge of LPAPW.

With respect to the origin of the measured levels, the objective was to obtain measured levels of knowledge plus two additional perceived levels (regarding the recommendations and benefits of LPAPW). Self-perceived knowledge was also measured (an overall measure) by Ferraro ${ }^{21}$, but he did not propose measures of verified knowledge. The combination of perceived and verified knowledge may be useful in studies that apply these statistics to determine whether knowledge is under or overestimated in the subjects. In later studies the QCAF-PROFI|LG ${ }^{25}$ was used to answer this question, demonstrating suitable agreement between verified and perceived knowledge in groups of professionals. A good cost-benefit relationship was shown to obtain a diagnosis based only on two questions related to perceived knowledge level.

The number of questions ( $\mathrm{n}=14$ ) on the QCAF-PROFI $\mid \mathrm{LG}^{25}$ is the same as in the study by Entil and Munhall (2006) $)^{20}$, and fewer than questionnaires used in studies in the state of Michigan ${ }^{19}$ (31 questions) and with obstetricians (36 questions) in São Paulo state ${ }^{17}$. Nevertheless, questions about the variables present in the QCAF-PROFI $\mid \mathrm{LG}^{25}$ questionnaire, related to the type of physical activity and its benefits for the fetus/baby seem to be nonexistent. This information is important, given that better clarification about these two aspects may improve professional counseling and the adherence of women to LPAPW. As a complement, the QCAF-PROFI $\mid \mathrm{LG}^{25}$ also considered the variables present in other surveys, such as questions on contraindicated physical activities ${ }^{18}$, frequency ${ }^{18}$, time/duration ${ }^{18,20}$, 
intensity ${ }^{18}$, benefits for maternal health ${ }^{20,26}$ and absolute contraindications for leisure physical activity during pregnancy ${ }^{18}$.

Within the typology of measuring knowledge are questionnaires with response options on a Likert scale ${ }^{26,20,18}$, differential semantic scale ${ }^{19}$, multiple choice $e^{20,19,26}$, dichotomic responses ${ }^{18}$ and open responsess ${ }^{19,18}$. The QCAF-PROFI|LG ${ }^{25}$ questions, in turn, have two types of response options (multiple choice and in combination with open responses), since the intention was to facilitate obtaining a metric from correct responses and based on a national reference study. To that end, when attributing the QCAF-PROFI $\mid \mathrm{LG}^{25}$ score, a number of procedures similar to those proposed by Domingues et al. (2004) $)^{27}$, capable of generating information and not subtracting points for incorrect responses, were applied.

The method applied to analyze questions is another positive point to underscore, since a recent extensive literature review containing all the guidelines on leisure physical activity for pregnant women was used to correct the responses ${ }^{14}$.

There are at least three limitations to this study. Although the questions used in the QCAF-PROFI|LG were examined by specialists, they were not from the maternal and child health area. This precaution was taken by Romero $(2012)^{17}$, who created a questionnaire based on a study by Entil and Munhall $(2006)^{20}$ and later submitted it to content validity by seven specialists in obstetrics and gynecology (medicine and nursing), physical education and statistics. These authors, in turn, conducted face validity based on the opinion of an obstetrician and Ferraro et al. $(2013)^{21}$ carried out a rigorous process to analyze reproducibility and face and construct validity.

The face and content validity used refers to the set of questions on the AI$\mathrm{PAF} \mid \mathrm{ABS}^{24}$ questionnaire, a fact that limited information, corrections and other questions that could be included in the QCAF-PROFI|LG. For example, other studies included questions on the type of physical activities indicated ${ }^{26,18}$, recommendations for previously active or sedentary pregnant women ${ }^{26,18}$ and specificities regarding aerobic exercises ${ }^{18}$. In contrast to the studies by Romero et al. $(2012)^{17}$ and Evenson and Pompelli $(2010)^{26}$, the QCAF-PROFI|LG ${ }^{25}$ does not contain questions by pregnancy trimester. Some of these limitations regarding non-included questions are explained by the fact that the QCAF-PROFI|LG originated in another questionnaire (AIPAF $\mid \mathrm{ABS}^{24}$ ) used for a comprehensive epidemiological study containing more than 100 questions. Therefore, we had to prioritize and limit questions to the most relevant for each life cycle.

There are at least three possible implications for physical activity and maternal and child health research from using the QCAF-PROFI $\mid \mathrm{LG}^{25}$. The first is academic, since epidemiological studies applying the QCAF-PROFI $\mid \mathrm{LG}^{25}$ may raise new hypotheses about the relevance of conceptual knowledge and variables associated with LPAPW. The second is social criticism, because it may reveal low levels of professional knowledge of the LPAPW in the public health context. Finally, there is an important practical implication, since, according to Barros et al. $(2015)^{23}$, the QCAF-PROFI|LG transforms knowledge into new resources. In this case, into a diagnostic tool for routine professional use to complement work processes involving permanent health education, with a focus on the PAPPW in terms of primary healthcare and the like.

It is suggested that future studies investigate the psychometric characteristics of the QCAF-PROFI|LG. There also seems to be a lack of instruments to measure the knowledge of Physical Education and health professionals regarding recommendations, benefits and negative effects of physical activities in the domestic, transport 
and work contexts. Likewise, questionnaires on the knowledge of professionals about sedentary behavior in pregnant women are needed. Moreover, other questionnaires aimed at collecting information on skills, practices and attitudes should also be conducted to better understand the competencies of health professionals in LPAPW.

In summary, this set of suggested diagnostic instruments, together with the satisfactory results for "test-retest" reproducibility and QCAF-PROFI|LG validity, may help in the comprehensive care of women in the maternal and child health network.

\section{Authors' contributions}

Fonseca, SA was responsible for the conception of the article, analysis and interpretation of the data and writing the article. Silva, JRA, Lemos, EC and Barros, MVG were responsible for conception of the article, analysis and interpretation of the data, critical revision and approval of the submitted version.

\section{Referênces}

1. Mudd LM, Owe KM, Mottola MF, Pivarnik JM. Health Benefits of Physical Activity during Pregnancy: An International Perspective. Med Sci Sports Exerc. 2013;45(2):268-77.

2. Thangaratinam S, Rogozinska E, Jolly K, Glinkowski S, Roseboom T, Tomlinson JW, et al. Effects of interventions in pregnancy on maternal weight and obstetric outcomes: meta-analysis of randomised evidence. BMJ. 2012;16;344:e2088.

3. Kasawara KT, do Nascimento SL, Costa ML, Surita FG, e Silva JL. Exercise and physical activity in the prevention of pre-eclampsia: systematic review. Acta Obstet Gynecol Scand. 2012;91(10):1147-57.

4. Hegaard HK, Hedegaard M, Damm P, Ottesen B, Petersson K, Henriksen TB. Leisure time physical activity is associated with a reduced risk of preterm delivery. Am J Obstet Gynecol. 2008;198(2):180.e1-5.

5. Domingues MR, Barros AJ, Matijasevich A. Leisure time physical activity during pregnancy and preterm birth in Brazil. Int J Gynaecol Obstet. 2008 ;103(1):9-15.

6. Takito MY, Benício MH. Physical activity during pregnancy and fetal outcomes: a casecontrol study. Rev Saude Publica. 2010; 44(1): 90-01.

7. Dumith SC, Domingues MR, Mendoza-Sassi RA, Cesar JA. Atividade física durante a gestação e associação com indicadores de saúde materno-infantil. Rev. Saude Publica. 2012; 46(2): 327-33.

8. Prather H, Spitznagle T, Hunt D. Benefits of exercise during pregnancy. PM R. 2012; 4(11):845-50.

9. Domingues MR, Barros AJ. Leisure-time physical activity during pregnancy in the 2004 Pelotas Birth Cohort Study. Rev Saude Publica. 2007;41(2):173-80.

10. Romero SCS, Kurashima CH, Romero A, Takito, MY. A influência dos profissionais de saúde sobre a prática de atividade física no lazer em gestantes. Pensar a Prática. 2015; 18(3):584-99.

11. Wojtyła A, Kapka-Skrzypczak L, Paprzycki P, Skrzypczak M, Biliski P. Epidemiological studies in Poland on effect of physical activity of pregnant women on the health of offspring and future generations - adaptation of the hypothesis development origin of health and diseases. Ann Agric Environ Med. 2012;19(2):315-26.

12. Pearce EE, Evenson KR, Downs DS, Steckler A. Strategies to Promote Physical Activity During Pregnancy: A Systematic Review of Intervention Evidence. Am J Lifestyle Med. 2013;7(1):38-50.

13. Evenson KR, Barakat R, Brown WJ, Dargent-Molina P, Haruna M, Mikkelsen EM, et al Guidelines for Physical Activity During Pregnancy Comparisons From Around the World. Am J Lifestyle Med. 2014;8(2):102-21.

14. Fonseca, SA. Promoção da atividade física para gestantes na atenção básica à saúde da região metropolitana de Recife: Projeto SUS+Ativo [tese de doutorado]. Florianópolis: Universidade Federal de Santa Catarina; 2014.

15. Mendes, EV. As redes de atenção à saúde. Brasília: Organização Pan-Americana de Saúde. 2011. 
16. Nascimento, JV. Perspectiva de intervenção profissional em Educação Física e esportes para o século XXI. IN: Sonoo, CN, Souza C, Oliveira, AAB (orgs). Educação Física e Esportes; os novos desafios da formação profissional. $1^{a}$ ed. Maringá: 2002, p. 17-36.

17. Romero SCC, Silva MAG, Carvalhaes MABL, Santos SM, Takito MY. Condutas de obstetras acerca do exercício físico na gestação. Revista Corpoconsciência. 2012;16(2):46-60.

18. Romero SCC. Gestação Ativa: a influência do profissional de saúde no comportamento da mulher [dissertação de mestrado]. São Paulo: Universidade de São Paulo. 2014.

19. Bauer PW, Broman CL, Pivarnik JM. Exercise and pregnancy knowledge among healthcare providers. J Womens Health (Larchmt).2010;19(2):335-41.

20. Entin PL, Munhall KM. Recommendations regarding exercise during pregnancy made by private/small group practice obstetricians in the USA.J Sports Sci Med. 2006;5(3):449-58.

21. Ferraro ZM, Boehm KS, Gaudet LM, Adamo KB. Counseling about gestational weight gain and healthy lifestyle during pregnancy: Canadian maternity care providers' selfevaluation. Int J Womens Health. 2013;(30)5:629-36.

22. Victora CG. Epidemiologia materno-infantil na América latina: reflexões sobre uma prática. Saúde, Ciência e Sociedade. 1992; (1)1:38-41.

23. Barros MVG, Brito ALS, Lemos EC, Bezerra J. Pesquisa e pós-graduação em atividade física relacionada à saúde: avanços, hiatos e implicações na intervenção profissional. Rev Bras Ativ Fís Saúde. 2015; 20(3): 209-13.

24. GPES: Grupo de Pesquisa em Estilo de Vida e Saúde. Disponível em http://www.gpesupe. org/downloads.php Acessado em 10/12/2015

25. MAFiCS: Medidas da Aptidão Física, Atividade Física e do Comportamento Sedentário. Disponível em https://questionariosite.wordpress.com/ciclos-da-vidas/atividadesfisicas-para-gestantes/ Acessado em 10/12/2015

26. Evenson KR, Pompeii LA. Obstetrician practice patterns and recommendations for physical activity during pregnancy. J Womens Health (Larchmt). 2010;19(9):1733-40.

27. Domingues MR, Araújo CLP, Gigante DP. Conhecimento e percepção sobre exercício físico em uma população adulta urbana do sul do Brasil. Cad Saude Publica. 2004; 20(1):204-215.

CORRESPONDING AUTHOR

SILVIO APARECIDO FONSECA

silviouesc@gmail.com
Universidade Estadual de Santa Cruz,

Departamento de Ciências da Saúde,

Ilhéus, BA, Brazil.

Av. Tancredo Neves, 4900 / Condomínio

Mar à Vista, Rua F, Casa 3. Nossa Senhora

da Vitória. 45655-650 Ilhéus/BA, Brazil.

5573 3632-9431
RECEIVED

$02 / 12 / 2015$

$31 / 05 / 2016$

$27 / 06 / 2016$

APPROVED 28/06/2016 